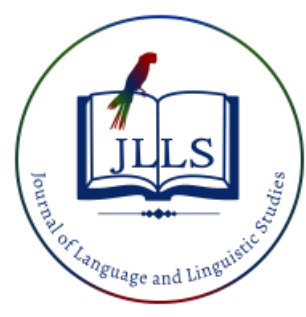

Available online at www.jlls.org

JOURNAL OF LANGUAGE

AND LINGUISTIC STUDIES

ISSN: $1305-578 \mathrm{X}$

Journal of Language and Linguistic Studies, 17(3), 1312-1324; 2021

\title{
The cognitive function of a conceptual metaphor and its methodological
}

\section{foundations}

${\text { Ulzhan U. Beknazarova a }{ }^{\text {ID }} \text {, Assiya B. Almautova }}^{\text {b iD , Shynar M. Yelemessova }}{ }^{c}$ iD,
Shyrynkul K. Abadildayeva ${ }^{\text {d iD }}$

a,b,c,d Korkyt Ata Kyzylorda State University, Kyzylorda, Republic of Kazakhstan

\section{APA Citation:}

Beknazarova, U. U., Almautova, A. B., Yelemessova, S. M., \& Abadildayeva, S. K. (2021). The cognitive function of a conceptual metaphor and its methodological foundations. Journal of Language and Linguistic Studies, 17(3), 1312-1324. Doi: 10.52462/jlls.94

Submission Date:21/05/2021

Acceptance Date:22/08/2021

\begin{abstract}
The theory of metaphor has gone through its development, starting with the works of Aristotle, in which it was begun, to the present state, when the linguistic paradigm became anthropocentric, and all linguistic phenomena are considered in direct connection with a person, his thinking, with society. The metaphor, which manifests the principle of human analogue thinking, occupies one of the central places in the cognitive direction of linguistic research. The cognitive theory explores metaphor as a means of conceptualising reality, as a basic mental operation that combines various conceptual spheres to explain, characterise, and cognise one with the help of the other. The novelty of the research is determined by the fact that in traditional theories (comparison theory, semantic approach) metaphor was perceived only as an unusual use of the word, as an abbreviated comparison, or investigated its semantic side, but did not pay attention to the reasons for the emergence of the metaphor, its essence, nature, its mechanisms generation, its role in the process of thinking and cognition. The authors show that the further development of the theory of metaphor is observed in close connection with the development of cognitive linguistics. The practical significance of the research is determined by the fact that the metaphor is shown not only as a phenomenon of language, but also one of the main means of thinking.
\end{abstract}

Keywords: creation of vocabulary; conceptualisation of reality; expressive means of speech; antique rhetoric; metaphor

\section{Introduction}

Metaphor is one of the means of secondary nomination, the essence of which is the use of a word denoting a certain object (phenomenon, action, feature) to nominate another object based on the similarity that follows from their comparison, matching with the association. The metaphor became the object of scientific research in antiquity. Thus, ancient theorists (Aristotle, Demetrius, Cicero) noted that in artistic speech, metaphor is one of the key components of the writer's style, the meaning of his work. According to H. Ortega y Gasset, a metaphor is needed not only to make a thought

\footnotetext{
${ }^{1}$ Corresponding author.

E-mail address: u.beknazarova5655@ust-hk.com.cn
} 
available to other people thanks to a name received; people themselves need it in order for the object to become more accessible to a thought. Metaphor is not only a means of expression, it appears as an important tool for thinking (Issakova et al., 2020; Temirbolat et al., 2017).

The ancient Greek philosopher and scientist Aristotle defined metaphor as a kind of a special word, describing it as a way of rethinking the meaning of a word based on similarities. Aristotle noted that a metaphor represents the transfer of a name from an object designated by that name to some other object. In his opinion, the metaphor participates in the creation of an individual artistic image of the world in artistic broadcasting, while revealing the peculiarities of the author's creative individuality. Aristotle's understanding of metaphor was considered classic: metaphor was the privilege of rhetoric and oratory. Demetrius advised using metaphors, because they "most of all make storytelling pleasant and majestic," however, according to the author, they should not be too frequent, otherwise "instead of describing, there will be praises".

\subsection{Literature Review}

Several main approaches have emerged in defining the essence of metaphor as a means of secondary nomination in modern linguistics (Gorbunova\& Wei, 2019). The first approach qualifies metaphor as a lexicological phenomenon. Its supporters believe that the metaphor is realised in the structure of the linguistic meaning of a word (Van Ments et al., 2016). This approach involves the identification and classification of the linguistic qualities of a metaphor (morphological, derivational, syntactic). Here, the interpretation of the metaphor is based on highlighting the semantic process, when the form of a linguistic unit or the design of a linguistic category is transferred from one designation of an object to another based on the similarity between these objects, and the derived meaning of the linguistic unit formed on the basis of the named semantic process (Yi \& Caiyun, 2019; Issakova et al., 2021).

Within this approach to the interpretation of metaphor, it has been argued that it necessarily involves comparison (Huang et al., 2013). The term "metaphor" refers to a unit consisting of two interrelated parts: "content" and "shell". The envelope "is not simply the decoration of the content, which remains unchanged: the envelope and the content give in their interaction a richer meaning than each of these components taken separately. They emphasise that comparison is a psychological process, and metaphor is a type of language use (Kertész et al., 2012). It should be noted that researchers do not understand comparison in the same way, namely: the combination of two objects for the purpose of their joint functioning; examining two objects to identify their similarities or differences (Burmeister, 2005). In this regard, it is proposed to distinguish between metaphors, which are based on a direct similarity between two objects, and metaphors based on the general relationship that is experienced towards both objects (Podvesovskii \& Isaev, 2018a). This distinction is not finite (Remias, 2018). The common characteristic of both objects is that they are liked, although at the same time there is no similarity between them. The metaphor is an abbreviated comparison, as the thought it evokes is about similarity and analogy (Eryomina, 2017; Kolesnikova et al., 2020).

Proponents of the second approach interpret metaphor as a logical operation involving the transfer of a word-concept from one group to another. The logical approach erases the difference between language metaphors and style metaphors (Podvesovskii \& Isaev, 2019). It teaches to duplicate signs from an object, turning the world of objects into a world of meanings (Ospanova et al., 2020). The metaphor is considered as a means of creating the vocabulary of the "invisible world", reflecting the inner life of a person (Fan, 2018). During the expression of emotions, a consolidated image of feelings arises. It finds itself in a set of predicates that contradict each other from the point of view of the logic 
of the objective world, and a world of the soul subordinate to a special logic is created (Wawrzyniak, 2014; Garipova et al., 2019).

The third, cognitive approach has become dominant in modern linguistics (Gibbs, 2006). Its supporters viewed metaphor as a means of conceptualising reality. Cognitive studies of the mechanisms of metaphorical conceptualisation are caused by a change in the static view of the world as a rigidly determined system of components, by considering the universe as a dynamic system that unfolds around a person (Ulybina, 2008; Zyubina et al., 2020; Temirbolat et al., 2016).

In 1980 the scientific work of D. Lakoff and M. Johnson "Metaphors We Live By" saw the light of day, in which linguists criticise the classical views on the concept of metaphor and prove that it is the basis of human thinking and everyday communication. In this study, they are presented as concepts through which a person perceives the world around him (Madsen, 2016). The discovery of D. Lakoff and M. Johnson began a new era in the history of the study of this secondary nomination tool. It began to be viewed as a deep concept of human consciousness, which determines a person's perception of the surrounding world (Gillan et al., 1995; Mazhitayeva et al., 2014).

Consequently, a metaphor appears in language when reality generates certain associations of the subject of cognition (Xia 2009). The process of the emergence of new knowledge is accompanied by comparison, drawing analogies between objects at the conceptual level, since this is inherent in the very nature of human mental operations (Podvesovskii \& Isaev, 2018b; Sultan et al., 2016). It is a means of secondary nomination and is a complex and multifaceted phenomenon (Hasanov et al. 2015). It represents innovative knowledge about the world through the use of resources available in the language, reflecting the variable diverse cognitive activity. Metaphor is an everyday phenomenon that has entered all spheres of life, the place and way of revealing which is not only language but also thinking and actions.

\section{Methodology}

Linguistic analysis shows that metonymy is constantly in the background compared to metaphor, which is much more often the subject of individual linguistic studios than metonymy, which "accompanies" research on metaphor, and only in some cases is the central object of linguistic studios. Given the semantic nature and structure of metonymy, this phenomenon was often identified with metaphor or considered as a kind of it. Carried away by metaphor and having devoted so many publications to it, the scientists kind of pushed metonymy into the background.

For many years, scientists have studied metonymy only as an important type of speech figure, the essence of which lies in the process of replacing one linguistic statement with another. The general features of the theory of metonymy were defined in ancient rhetoric against the background of the doctrine of metaphor. In the rhetorical tradition, metonymy was interpreted as an insignificant fact of speech, as a means of embellishment. Differences in the interpretation of metonymy between ancient authors were mainly in the extent to which a particular rhetorician assessed its ability to embellish, that is, to enhance the expressiveness of speech. The metonymy of the rhetorical tradition is an expressive means, an element of the elocution stage - the choice of linguistic units. It was at this time that a subinstitutional approach to the interpretation of metonymy was formed. Representatives of this approach believed that metaphor is the most beautiful and most common of the types of lexemes, therefore metonymy was mainly considered its kind. Metonymy and synecdoche were not isolated. They were put into one group of figurative words.

However, in the development of the tendency to delineate tropes, some rhetoricians, in particular Quintilian and Theophrastus, began to investigate metonymy as a phenomenon other than metaphor. At the same time, attention was focused on the linguistic mechanisms of the formation of metonymy, 
on the classifications and functional features of this path. Then there was a definition of metonymy as a trope, which is replacing the name of one phenomenon with another. Metonymic were such sayings that borrowed names from close and related objects that were not called by their real names. These names are formed on behalf of their creator, or are borrowed from an invented object or tools, are transferred to an owner, or what is being done, what is doing, or what is contained, on a holder, or from a holder to a held.

However, despite the observance of the postulates of this approach to the interpretation of metonymy, the views of the rhetoricians on certain aspects of the functioning of this trope differed. So, Quintilian, Cicero, Demetrius considered metonymy as an adornment of rhetorical utterances, where, thanks to substitution, a deliberate deviation from the usual use of the word is created, which embellishes the speech and attracts a listener's attention. Theophrastus, Dionysius considered metonymy to be a device that first of all imparts splendour to the poetic style.

\section{Results and Discussion}

For the first time, metonymy acquires a theoretical foundation in the context of developing the foundations of oratory. On the one hand, in ancient rhetoric, there is a tendency to combine metaphor and metonymy through the dominance of metaphor as the main trope. On the other hand, there is a gradual distinction between metaphor and metonymy, associated with the study of other tropes separately from metaphor. The metaphor is based on the use of a word denoting a certain object for the nomination of another object on the basis of analogy, and a name is chosen by analogy, and metonymy is the extraction of a property from the reality already reflected in the language due to its contiguity with the property of the new denoted and the choice of its name that reflects this contiguity in its semantics.

Metonymy was considered as an expressive means and as one of the types of polysemy. At the present stage, the research of metonymy takes place in several directions: in relation to metaphor and synecdoche; on certain types of metonymy of connections and transfers; hyphenation metonymy at the grammar level is analysed. The linguistic concept of metonymy is not homogeneous, since this term is used not only to determine the type of path, but also to determine one of the paths of the historical development of the meaning of this word. It is indicative that even in the structure of the polysemantic term "metonymy" one can trace the metonymic transfer according to the "process - result" model, namely: metonymy is one of the main tropes in poetic and everyday speech, which is based on the transfer of a name from one concept to another that is in connection with him, as well as a word or expression in such a meaning. Today, four main approaches have been formed in the study of metonymy: psychological, lexical-semantic, semantic-syntactic and cognitive (Atabekova, 2020).

The psychological approach dates back to ancient times. It is based on psychological associations for related factors that reflect the connections that actually exist between objects and phenomena of the surrounding reality. Representatives of the psychological direction interpreted paths and figures from the standpoint of living speech, speech processes. The focus is on the sensory image, which forms certain judgments through the act of analytical cognition. The central concept is "image", through the prism of which a person passes to the knowledge of an object, as well as "thought", which forms a concept from the sensory images of an object. The reason for the appearance of images is the specificity of the human mind and the inability to absolute abstraction. The main reason for the development of meanings is the instability of the individual psyche and word usage (Beknazarova et al., 2020).

Metonymy, like metaphor, is based on an association between two ideas. There are two types of associations: association between meanings and association between names. Metonymy presupposes 
not logical understanding and logical deployment, but psychological understanding and psychological deployment, the main operation of which is a focus. Most of the images are the result of necessity or misconceptions or false analysis, ignoring their historical and social significance. Analysing the psychological and linguistic mechanisms of metonymy as a semantic and stylistic phenomenon, they noticed that the law of contiguity association is connected with the perception of objects in space, and the law of sequence - with perception in time, which makes it possible to expand the scope of metonymy.

The main reason for the metonymy of transfers, according to the supporters of the psychological direction, is the logical relationship between the concepts of adjacent objects and psychological associations for related factors, which make it possible to transfer the names of one object to another. However, it is noted that this approach to the study of metonymy is not accurate enough, since the characterised concept expressed by a figurative meaning is not generic with respect to the one that characterises, but has a slightly different qualitative meaning.

The second, lexico-semantic approach, attempts to explain the semantic mechanism of metonymy creation using component analysis. The object of study is the meaning of the derived word and the role of the lexical environment for specifying this meaning. Proponents of this approach insist on solving the problem of changing the seme composition of words used metonymically. Metonymic transfer is explained by the redistribution of the original word and, as a result, a new archiseme appears in the derived word (the general seme of the generic concept), which reflects the features inherent in entire classes of objects. The previous archiseme turns into a differential seme for a derived word, which helps to distinguish the meanings of words (Atabekova \& Shoustikova, 2018).

Within the framework of the lexical-semantic approach, scientists consider the metonymic transfer in terms of expression, and the concept that the cause of the metonymic transfer is the semantic narrowing of a sentence is quite common. Metonymy is one of the universal habits of thought, its undisclosed form exists, the need to capture not only the similarity of ideas, but also their relationship: A (image) precedes X (meaning)... All cases of metonymy observed in language have one common character: the transition of thought from a more specific to a more distant, abstract meaning, the replacement is closer in time to the perception of the one that comes to consciousness later. The lexical-semantic approach cannot claim universality, since the separation of semes is random, and there are no criteria that would help to determine the number of components.

The third, semantic-syntactic, approach treats metonymy not as a figure of speech, but as an element of the general process of speech. By linking metaphor and metonymy with the two main axes of the structure - paradigmatic and syntagmatic, the metaphor is built on the substitution of a concept on the paradigmatic axis, which is associated with paradigmatic connections by similarity, and metonymy is oriented towards the syntagmatic axis, towards establishing connections by contiguity. One topic can pass into another by similarity or by contiguity, however, for the first case, the term "metaphor axis" will be a convenient way of designation, for the second - "metonymy axis".

Some linguists believe that metonymy is the result of a transformation of syntactic structure. The main feature of metonymy is a change in the hierarchy within the syntactic structure, which does not change the semantic components. The principle of the structure of metonymy (part of the whole) affects not only the syntactic connections of the corresponding words, but also the compatibility of other words. In this case, the lexical change of the word does not occur. Distinguishing metaphor and metonymy as two poles in the system of tropical means presupposes an extended interpretation of metonymy. It is understood as a metonymic way of storytelling, reflecting the author's linguistic creativity, when the transition from one topic or thought occurs on the basis of adjacent associations, that is, metonymically. 
Proponents of the cognitive approach define metonymy as a cognitive process in which one conceptual entity - a theme - replaces another conceptual entity - an image - within one sphere. The modern theory of cognitive metonymy arose on the basis of the theory of cognitive metaphor. In their research, scientists consider metaphor and metonymy not only as a phenomenon of language, but as the main ways of thinking. Thus, they emphasise the fact that human cognition is largely shaped by transferable processes. The advantages of modern rethinking of traditional tropes lie in a new approach to the very mechanism of creating these phenomena: it is not the semantics of the tropes that are important, but the various and complex forms of the interpenetration of the conceptual, linguistic and artistic spheres (Moldagali et al., 2018).

Metonymy makes it possible to combine two factors - the speaker's desire to express himself accurately (in order to correctly direct the addressee's attention) and the natural tendency to think and talk about those things that have the greatest cognitive meaning for him. A well-chosen metonymic expression allows a person to remember an entity that has more cognitive meaning and a simpler linguistic expression, thereby causing the idea of another entity, less highlighted or with a more complex designation. Cognitive research on metonymy has identified an opportunity to look at this phenomenon differently. The cognitive direction, based on all the previous experience of traditional linguistic research, allows identifying the mental foundations of linguistic phenomena and significantly expand the views on metonymy. Within the framework of the cognitive approach, metonymy is considered not only as a linguistic phenomenon, but also as a fundamental property of our consciousness, as one of the principles of organizing everyday thinking and a certain way of conceptualising and categorizing reality. It is the main cognitive process in which one concept provides access to another related, adjacent one, which plays an important role in structuring the conceptualisation of human experience.

The cognitive definition of metonymy does not completely deny the traditional analysis of metonymy in terms of contiguity, if it is understood as conceptual contiguity (concepts within one frame are linked by a conceptual contiguity relationship with other concepts within the same frame. Two concepts that take part in the "birth" of metonymy, are components of one conceptual complex, that is, they are adjacent (related) elements within the same ideal cognitive model, and the integrity of a certain conceptual complex of concepts is motivated by human experience. The cognitive approach to the study of metonymy has incorporated the achievement of traditional approaches. It makes it possible to expand the boundaries of the traditional understanding of this phenomenon, considering metonymy as a cognitive mechanism that is used for logical operations and judgment about the world, conceptualisation and categorization of ordering activities. The cognitive essence of metonymy is seen in the fact that during the process of metonimising one conceptual entity provides access to another conceptual entity within one conceptual sphere (Tussupbekova et al., 2019).

Z. Kövecses (2020) in his work discusses the components of the linguistic cognitive view of metaphor and indicates how the metaphor is understood in accordance with this point of view. Metaphor is not an exclusively linguistic phenomenon, but a multifaceted phenomenon that affects not only language, but also the human conceptual system, sociocultural practices, as well as neural and bodily activity. According to the central thesis of the cognitive theory of metaphor, metaphorisation processes are based on procedures for processing knowledge structures - frames and scenarios. Knowledge realised in frames and scenarios, is a generalized experience of human interaction with the surrounding world of physical objects and society. Thus, the metaphor becomes a cognitive mechanism that determines a person's thinking, and is inherently a phenomenon that provides understanding. A special role is played by the experience of direct interaction with the material world, which is reflected in the language, in particular through ontological metaphors, metaphors of transmission and the visual communication channel: to catch a sign, to cast a glance, to give a wink. 
As is known, metaphorisation is based on the interaction of two knowledge structures: the cognitive structure of the source (source domain) and the cognitive structure of the target (target domain). In the process of metaphorisation, some target areas are structured according to the principle of the source, that is, metaphorical mapping or cognitive mapping occurs. Metaphorical projection is found at the level of semantics of the sentence and text in the form of metaphorical formations. For example, the ontological metaphor GLANCE (goal) is a physical OBJECT (source) in the statement "they exchanged meaningful glances" appeals to the idea of the materiality of the message through the look and expression of the eyes, which is part of the cognitive structure (frame) of the message: after all, human knowledge of the world confirms that messages, for example, in the form of a written letter as a prototype version, is a material object. The illumination (salience) of an individual feature of the source, in particular through the relative adjective meaningful, in the field of the goal in the process of metaphorical projection is profiling (Aubakirova, 2016).

Source and target zones are not equivalent. The first is based on concrete, basic knowledge acquired by a person in the process of direct contact with reality, and is a generalization of a person's practical experience in the world. The target area includes less specific and less precise knowledge that requires understanding, specification and structuring. Metaphor allows rather abstract and inherently unstructured entities to be understood in terms of more concrete, more structured entities. Knowledge in the source area is organised in the form of image schemas, which are relatively simple cognitive structures that are regularly updated in the process of the individual's physical interaction with reality. Schemes include categories such as container, path, balance, top - bottom, part - whole, etc.

The authors distinguish between the concepts of metonymy and synecdoche, which is also one of the ways of forming secondary nominative content. It should be noted that the question of the relationship between metonymy and synecdoche is solved ambiguously. Many researchers consider synecdoche as a kind of metonymy on the grounds that synecdoche is very close to metonymy and there is no exact border between them. Synecdoche is a type of metonymy, which is based on the contiguity of a quantitative nature in the relationship between a whole or something larger in general and its part or something smaller in general, between a certain set and its separate element. With the help of the synecdoche, something is closer, can already act as a sign of further, wider and vice versa, further away - as a sign closer. Synecdoche substitution is externally similar to the metonymic (in both cases it is about objective connections between closely related concepts or phenomena).

Synecdoche as a kind of metonymy is analysed indicating that most metonymy relations in their most general form can be reduced to synecdochial (part instead of whole and whole instead of part), synecdochemical names of a person for a part of the body, a piece of clothing, or for other specific signs. Synecdoche is considered a kind of metonymy and it is thought that it is due to the interaction of the concepts of the part and the whole. Adjacency becomes the basis for distinguishing various types of metonymy - causal, attributive, spatial, temporal, quantitative. Other views on the coexistence of these linguistic phenomena are also known. Metonymy should be interpreted as an initial trope, which is based on a chain of associative adjacencies. At the same time, representatives of the Liege group argue that there are intermediate forms of tropes that interact with each other. The main figure is proposed to be considered a synecdoche (Altay et al., 2015).

Synecdoche is not a kind of metonymy. Synecdoche does not take the artist beyond the entire defined range: part - whole, species - genus. The synecdoche of a real artist is always original and occupies a special place. This is an artist's play with concepts by changing their volume for the sake of expressiveness. But by naming a part instead of a whole, the artist means the whole, thereby emphasizing the characteristic in the image. Synecdoche helps to express a lot, moreover, in fewer words. Synecdoche is often used in everyday speech. 
Taking into account all the previous interpretations, the authors submit their interpretation of metonymy in artistic speech. In the authors' opinion, metonymy is a semantic process in which the linguistic design of various contiguity relations arises, they are established by human consciousness between the conceptual categories of objectivity, quantity, belonging, and the like. The authors define synecdoche as one of the types of metonymy, in particular the quantitative type of semantic transfer.

The anthropocentric principle of the cognitive direction of linguistics plays an important role in the teaching of metaphor. The opinion is expressed that the most characteristic parameter of the metaphor is precisely anthropocentricity. It is expressed in the fact that the choice of one or another basis for a metaphor is associated with a person's ability to measure everything new in the image and likeness to himself or according to the objects with which a person deals in practical reality. It is believed that the choice of the necessary semantic features from a set of data in direct numerical expression for the implementation of the metaphorical interaction of two spheres of knowledge and their comprehension by the addressee is possible only under the conditions if the concept that is metaphorically expressed is already born in consciousness in any form, i.e. metaphor is understood as a way of thinking about the world that uses knowledge and experience gained earlier (Lypchanko-Kovachyk \& Sidun, 2019).

Researchers of the metaphor believe that it is also the main form of thinking of primitive man, and therefore, cultural, social, ethnic and other characteristics of the people are reflected in it. It is the metaphor that bears the signs of the evolution of the mentality. There is a close connection between the history of metaphor and the history of mentality. Metaphors should be seen as indicators of mentality that shape, implement and, so to speak, give language to mentality. As is known, the form of thinking of primitive man was a myth, however, researchers believe that mythological thinking is directly related to metaphor. The first to speak on this matter was the Italian rhetorician of the 18th century D. Vico, who believed that metaphor was the most necessary and used trope and by its nature constituted a small Myth. Later, his views were supported by most researchers of the metaphor.

Metaphoricity is a characteristic property of primitive thinking, when a person had not yet separated himself from nature, transferred his own actions and experiences to it. This is how the metaphors of the language arose, which are very common in Russian vocabulary. A person operates with many of them already unconsciously, not feeling their once fresh imagery. This fact is illustrated by the example of "the sun sets". Such expressions have become entrenched in the language, but it is hard to imagine the most separate act, which undoubtedly lives in the minds of ancient people. Only with the destruction of mythological thinking is their metaphorical nature realized (Kondratenko et al., 2021).

Mythological and linguistic thinking are intertwined. Both myth and language, as a direct exponent of thinking, originate in metaphorical thinking. Based on the ideas presented in the works on the origin of language, which emphasized the originally mythological nature of all verbal and linguistic concepts and believed that at the heart of any myth is a basic metaphor. A basic metaphor theory was developed. It would be impossible to master the external world, to know and understand it, to comprehend and name its realities without this basic metaphor, that universal mythology, this blowing of the spirit into the chaos of objects and creating it in human image and likeness (Hoqueet al., 2021).

Basic metaphors are considered as convoluted formulas of holistic ritual magical actions, mythological representations, as well as a totemistic worldview, in which a person identified himself with the surrounding reality. Therefore, it can be said that metaphor was the first form of reflection of reality, the way of thinking of a person and the basis for the emergence of a word - the designation of a certain object or phenomenon. Within the framework of cognitive linguistics, the cognitive theory of metaphor appears, which was first presented in the work of D. Lakoff and M. Johnson. They consider metaphor not only as a phenomenon of language, but also as one of the ways of thinking, processing 
information and acquiring knowledge. In cognitive science, a metaphor is not a figurative means that connects two meanings of a word, but a basic mental operation that unites two conceptual spheres.

In the cognitive theory, metaphor becomes an important element in structuring reality with the help of language. It structures reality in a double sense, which is proposed to be considered using wellknown examples. On the one hand, such conceptual metaphors appear quite naturally from the experience of cognizing reality, and on the other, they simultaneously influence this experience and, accordingly, actions. Thus, a metaphor is not only an exponent of ideas about reality, but also a tool for influencing thinking, creating a certain view of objects, things, events. Metaphors are, as it were, a mediator between the surrounding world and human consciousness. The cognitive theory of metaphor examines, in particular, the conceptual (D. Lakoff's term) metaphor, which is understood as the result of the reflection of knowledge about one conceptual area in another conceptual area. They offer a narrower definition of conceptual metaphors - stable correspondences between the region of the source and the region of the goal, which are fixed in the linguistic and cultural tradition of this society.

The main components of a conceptual metaphor are a conceptual referent, a conceptual correlate, a metaphor base and a context. The conceptual referent (it is also called the mental sphere-target, denotative zone, recipient sphere, direction of metaphorical expansion) is understood as the denotative substrate that is identified with the help of metaphor, the conceptual correlate (in other terms - the mental sphere-source, sphere-donor, source metaphorical expansion) is a concept drawn to comparison; the basis of the metaphor is the relationship between the referent and the correlate, which contains a certain aspect for comparison, a common feature. The context is then decisive for the choice of the aspect of similarity (Nontasee \& Sukying, 2021; Kiporenko \& Kuprata, 2021).

Many researchers analyse the metaphor of a certain discourse, limited by any criterion, within the framework of the cognitive theory by considering the metaphorical models of this discourse. Representatives of the school of cognitive linguistics understand by a metaphorical model a set of linguistic means that figuratively represent one or another conceptual sphere, the content of which is united by one name. Examples of metaphorical models are given, distinguishing models of war, mechanism, organism, theater, medicine. Metaphorical models are embedded in the conceptual system of the human mind, this is a kind of scheme according to which a person thinks and acts. It is proposed to consider metaphorical models as a whole, which has its own scenario, a set of frames and slots.

It turned out that a conceptual metaphor is not only a means of defining the material world, but also a means of finding abstract beings, the formation of "concepts" of the corresponding or linguistic concepts. Metaphors expressing concepts in figurative text are expressed in the following form (Table $1)$.

Table 1. Forms of expression of Metaphors that express concepts in figurative text,

\begin{tabular}{|c|c|c|}
\hline Forms & Forms & Expression \\
\hline Abstract & Real & $\begin{array}{c}\text { An image of an } \\
\text { abstract concept } \\
\text { with real meaning. }\end{array}$ \\
\hline Real meaning & Abstract & $\begin{array}{l}\text { Representation of } \\
\text { specific concepts } \\
\text { in the abstract. }\end{array}$ \\
\hline Abstract & Abstract & $\begin{array}{l}\text { Representation of } \\
\text { abstract concepts } \\
\text { in abstract form. }\end{array}$ \\
\hline
\end{tabular}




\begin{tabular}{lcc}
\hline $\begin{array}{l}\text { Representation of the concept by } \\
\text { human action }\end{array}$ & - & - \\
$\begin{array}{l}\text { Demonstration of the concept } \\
\text { through the image of animals }\end{array}$ & - & $\begin{array}{c}\text { Zoomorphic } \\
\text { metaphors }\end{array}$ \\
\hline
\end{tabular}

Thus, the conceptual metaphor arises as a result of a metaphorical process aimed at creating a new concept. It plays a particularly active role in the formation of abstract meaning in language, based on the association of non-material concepts with the processes of perception, generalization, stabilization of human thinking and the processing and publication of one's own views. The names of actual, abstract concepts arising from the laws of the thought process, such as analogy, association in human cognition, the result of a new lexical meaning. Like all metaphors, a conceptual metaphor goes through a figurative stage, which loses its metaphorical properties when it becomes an internal state of language use and becomes a ready-made name. Conceptual metaphors are constant, figurative words are fluid and change with similar figurative words depending on the creative use of an addressee. While abstract concepts are the object of conceptual metaphor, figurative words are the object and form the basis of conceptual metaphor.

\section{Conclusions}

Thus, dwelling on the main provisions of the cognitive theory of metaphor, it can be concluded that with the development of cognitive linguistics, metaphor takes a leading place in its research. This fact is not accidental: the study of a metaphor proves its involvement in the processes of thinking, receiving, processing and transmitting information. The metaphor is directly related to the experience of a certain collective, people; it is in it, since ancient times, that people's thoughts regarding the surrounding reality have been embodied. Metaphor is a means of nomination, being the basis of similar thinking. Considering the metaphors of a specific language, one can comprehend the foundations of the culture of this ethnos, trace its formation, development in time.

The cognitive theory explores metaphor as a means of conceptualising reality, as a basic mental operation that combines various conceptual spheres to explain, characterise, and cognise one with the help of the other. In order to study metaphorics, the cognitive theory proposes an analysis of conceptual metaphors of a language, considering their structure, or metaphorical models that make up a set of metaphors from one conceptual area for an expanded image, explaining a certain phenomenon of a different conceptual area.

\section{References}

Altay, A., Aituganova, S., \& Aubakirova, K. (2015). The main features of translations of foreign literature by Jusupbekaimautuly: Cultural and historical differences. American Journal of Applied Sciences, 12(12), 1023-1031.

Atabekova, A. (2020). Language representation of youth health concept in international institutional discourse. Systematic Reviews in Pharmacy,11(12), 1417-1427.

Atabekova, A., \& Shoustikova, T. (2018). Language issues within forced migration at borders and temporary settlements: An integrated content analysis. European Research Studies Journal, 21, 690-700. 
Aubakirova, K.A. (2016). Nurturing and testing translation competence for text-translating. International Journal of Environmental and Science Education, 11(11), 4639-4649.

Beknazarova, U., Saduakasuly, Z., Suleimenova, Z., Saryshova, K. \& Abasilov, A. (2020). The conceptual metaphor of 'life is a journey' in Kazakh cognition. Opción, 36(27), 1339-1356.

Burmeister, D. (2005). The exchangeability of speech by cognitive metaphors. Proceedings of the International Conference on Information Visualisation, 89-96.

Eryomina, O. (2017). Cognitive function of a metaphor: observer's evaluation. Voprosy Kognitivnoy Lingvistiki, 2, 64-69.

Fan, L. (2018). Literature review on the cognitive approach to metaphor. Procedia Computer Science, $131,925-928$.

Garipova, V., Ayupova, R.A., \& Markova, E.M. (2019). Linguistic means of description of family relations in the novel In Chancery by J. Galsworthy. Journal of Research in Applied Linguistics, 10(Special Issue), 416-423.

Gibbs, R. (2006). Cognitive linguistics and metaphor research: past successes, skeptical questions, future challenges. Documentacao de Estudosem Linguistica Teorica e Aplicada, 22, 1-20.

Gillan, D., Fogas, B., Aberasturi, S., \& Richards, S. (1995). cognitive ability and computing experience influence interpretation of computer metaphors. Proceedings of the Human Factors and Ergonomics Society, 1, 243-247.

Gorbunova, L., \& Wei, C. (2019). Source domain of cognitive metaphor: status quo and prospects of research. Sibirskii Filologicheskii Zhurnal, 3, 158-169.

Hasanov, G., Mynbayeva, A., Duisenbayeva, G., Mukhamejanova, G., Aldasheva, K., \& Kongyratbay, K. (2015). Fundamentals of cognitive metaphor. Asian Social Science, 11(18), 8285 .

Hoque, M. A., Ali, M. M., Puteh-Behak, F., \& Baharun, H. (2021). Lexical borrowings from the English language into bangla short stories. Journal of Language and Linguistic Studies, 17(1), 158172.

Huang, X., Huang, H., Liao, B., \& Xu, C. (2013). An ontology-based approach to metaphor cognitive computation. Minds and Machines, 23(1), 105-121.

Issakova, S.S., Kultanbayeva, N.K., Kushtayeva, M.T., Saduakas N.A., Aitbenbetova, A.K., \& Imangazina, A.A. (2021). Fairytale discourse as a demonstration of the national mentality (On the material of Kazakh and Russian fairy tales). Astra Salvensis, 2021, 121-135.

Issakova, S.S., Sadirova, K.K., Kushtayeva, M.T., Kussaiynova, Z.A., Altaybekova, K.T., \& Samenova, S.N. (2020). World ethnocultural specificity of verbal communication: Good wishes in the Russian and Kazakh languages. Media Watch,11(3), 502-514.

Kertész, A., Rákosi, C., \&Csatár, P. (2012). Data, problems, heuristics and results in cognitive metaphor research. Language Sciences, 34(6), 715-727.

Kiporenko, A.Yu., \& Kuprata, N.Ya. (2021). Academic mobility of students of philological specialisations in the structure of polylingual intercultural education. Scientific Bulletin of Mukachevo State University. Series "Pedagogy and Psychology”, 7(2), 9-17. 
Kolesnikova, S.M., Markova, E.M., Burskaya, E.A., \&Chibisova, A.V. (2020). Concept of "family" in the Russian and Chinese linguoculture: Cognitive, phonosemantic and educational aspects. Asia Life Sciences,22(2), 229-242.

Kondratenko, N.Yu., Marchenko, H.V., \& Stezhko, S.O. (2021). Psychological and pedagogical principles of development of communicative competence of future journalists based on linguoculturology. Scientific Bulletin of Mukachevo State University. Series "Pedagogy and Psychology”, 7(1), 113-120.

Kövecses, Z. (2020). Extended conceptual metaphor theory. Cambridge: Cambridge University Press.

Lypchanko-Kovachyk, O.V., \& Sidun, M.M. (2019). Peculiarities of formation of linguistic of future teachers of foreign language. Bulletin of Mukachevo State University. Series "Pedagogy and Psychology”, 1(9), 83-88.

Madsen, M. (2016). Cognitive metaphor theory and the metaphysics of immediacy.Cognitive Science, 40(4), 881-908.

Mazhitayeva, S., Tazhikeyeva, A., Khan, N., Ayazbaeva, B., Tuite, E., Nygmetova, N., Sembiyev, K., $\&$ Kenzhegaliyev, S. (2014). Lexicon and national realias: Borrowed words, loan words, exoticisms, anglicism. Life Science Journal,11(Spec. Issue 6), 122-128.

Moldagali, B., Sagyndykuly, B., Akhtayeva, N.H., Boranbai, B.E., \& Tauova, O.G.S. (2018). Time in people's models of linguistic categorization. Analele Universitatii din Craiova - Seria Stiinte Filologice, Lingvistica, 40(1-2), 339-349.

Nontasee, W., \& Sukying, A. (2021). The learnability of word knowledge aspects in thai EFL high school learners. Journal of Language and Linguistic Studies, 17(1), 34-55.

Ospanova, Z., Tolybayeva, K., Nurkenova, S., Duisekova, K., \& Baltabayeva, G. (2020). Lingua and culture study research on indirect communication cognitive metaphor. Xlinguae, 13(2), 157-165.

Podvesovskii, A., \& Isaev, R. (2018a). Cognitive clarity criteria as a basis for constructing a visualization metaphor for fuzzy cognitive maps. In 28th International Conference on Computer Graphics and Vision, 158-162.

Podvesovskii, A., \& Isaev, R. (2018b). Visualization metaphors for fuzzy cognitive maps. Scientific Visualization, 10(4), 13-29.

Podvesovskii, A., \& Isaev, R. (2019). Assessing the quality of visualization metaphor of fuzzy cognitive maps on the basis of formalized cognitive clarity criteria. CEUR Workshop Proceedings, 2485, 103-107.

Remias, Y. (2018). Comparative theology and cognitive metaphor theory: an analogous reasoning. Studies in Interreligious Dialogue, 28(1), 1-28.

Sultan, Y., Alkebaeva, D.A., Kurkebayev, K.K., Abdikulova, R.M., \& Sagyndykov, N.B. (2016). The categories of time and space in modern novel transformation. Man in India, 96(10), 3927-3937.

Temirbolat, A.B., Daribaev, S.D., Imakhanbet, R.S., Ospanova, A.A., \& Ospanova, A.A. (2016). Influence of mass literature on the reader's consciousness. Global Media Journal, 2016, 1-6.

Temirbolat, A.B., Imakhanbet, R.S., Orda, G.Z., Ospanova, A.A., \& Omarov, T.K. (2017). Specifics of embodiment of the national idea in Kazakh literature. Man in India, 97(20), 435-445. 
Tussupbekova, M.Z., Idrissova, M.A., Smagulova, B.G., Kazhikenova N.K., Konyratbaeva, Z.M., \& Abduali, B. (2019). Action research in teaching English for students of non-linguistic specialties in higher schools. Journal of Social Sciences Research, 5(2), 354-359.

Ulybina, E. (2008). Lev Vygotsky's cultural-historical approach and cognitive metaphor theory development. Psikhologicheskii Zhurnal, 29(1), 119-125.

Van M., Thilakarathne, D. L., \& Treur, J. (2016).Modelling the role of cognitive metaphors in joint decision making. In 2015 IEEE/WIC/ACM International Joint Conference on Web Intelligence and Intelligent Agent Technology (WI-IAT), 67-75.

Wawrzyniak, A. (2014). Cognitive metaphors of the mind in the canterbury tales. Research in Language, 12(1), 49-60.

Xia, W. (2009). Reading based on metaphor theory in cognitive linguistics. In ETT 2009 - 2009 2nd International Conference on Education Technology and Training, 260-263.

Yi, S., \& Caiyun, J. (2019). A Study of emotional adjectives in teaching chinese as a foreign language: a perspective of cognitive metaphor theory. Chinese as a Second Language Research, 8(2), 249274.

Zyubina, I.A., Filippova, M.I., Minakova, N.A., Krivoshlykova, L.V., \& Anikejeva, I.G. (2020). Synchronous personal method of language studying speech behavior in implicit pragmalinguistics. XLinguae, 13(4), 81-90.

\section{AUTHOR BIODATA}

Ulzhan Beknazarova is Master of Science in Pedagogy, Doctoral Student, Department of Kazakh Language, Literature and Journalism, Humanitarian-Pedagogical Institute, Korkyt Ata Kyzylorda State University, Kyzylorda, Republic of Kazakhstan.

Assiya Almautova is Ph.D. in Philology, Senior Lecturer at the Department of Kazakh Language, Literature and Journalism, Humanitarian-Pedagogical Institute, Korkyt Ata Kyzylorda State University, Kyzylorda, Republic of Kazakhstan.

Shynar Yelemessova is Ph.D. in Philology, Senior Lecturer at the Department of Kazakh Language, Literature and Journalism, Humanitarian-Pedagogical Institute, Korkyt Ata Kyzylorda State University, Kyzylorda, Republic of Kazakhstan.

Shyrynkul Abadildayeva is Master of Science in Pedagogy, Senior Lecturer at the Department of Foreign Languages and Translation, Humanitarian-Pedagogical Institute, Korkyt Ata Kyzylorda State University, Kyzylorda, Republic of Kazakhstan. 